\title{
HORTAS EM ESPAÇOS URBANOS COMO FERRAMENTA DE EDUCAÇÃO AMBIENTAL, SEGURANÇA ALIMENTAR E QUALIDADE DE VIDA
}

\author{
Mariana Cereali ${ }^{1}$ \\ Suzete Rosana de Castro Wiziack ${ }^{2}$
}

Resumo: A partir de textos publicados em periódicos brasileiros, procuramos identificar as tendências de pesquisas sobre hortas em espaços urbanos. A coleta de dados em duas plataformas de produção científica no recorte de tempo de 2016 a 2020 teve, como objetivo geral, identificar o panorama das publicações que abrangem o desenvolvimento de hortas em ambientes urbanos, numa relação com a Educação Ambiental (EA) e a promoção de segurança alimentar. Concluiu-se que a execução de hortas urbanas, quando aliada à EA, exerce um papel importante para a comunidade ao entorno, auxiliando os indivíduos no entendimento crítico sobre o ambiente e sobre as necessidades nutricionais e sociais da comunidade.

Palavras-chave: Educação informal; Educação Formal; Hortas comunitárias; Alimentação.

Abstract: Based on texts published in Brazilian journals, we seek to identify trends in research on vegetable gardens in urban spaces. The data collected on two scientific production platforms, over a period of time from 2016 to 2020, had the general objective of identifying the panorama of publications covering the role of vegetable gardens in urban environments, in a relationship with Environmental Education and the promotion of food security. It is concluded that, the execution of Urban gardens, when allied to EA, play an important role for the surrounding community, helping individuals in the critical understanding of the environment, their nutritional and social needs.

Keywords: Informal Education; Formal Education; Community Gardens; Food.

\footnotetext{
1 Universidade Federal de Mato Grosso do Sul. E-mail: mcereali@gmail.com, Link para o Lattes: http://lattes.cnpq.br/3621584563905760

2Universidade Federal de Mato Grosso do Sul. E-mail: suzete.wiziack@ufms.br Link para o Lattes: http://lattes.cnpq.br/9661553680785951
} 


\section{Introdução}

A Educação Ambiental (EA), segundo a Lei n.9795 (BRASIL,1999), é um componente da educação nacional, estando, assim, presente em todos os níveis de ensino na educação formal e em propostas educativas não formais. $\mathrm{Na}$ educação formal, a EA é de extrema importância para diversas disciplinas do ensino, podendo estar aliada a projetos sociais que a escola desenvolve, como hortas comunitárias. Para tanto,

A Educação Ambiental, também chamada de eco educação, vai muito além do conservacionismo. Trata-se de uma mudança radical de mentalidade em relação à qualidade de vida, que está diretamente ligada ao tipo de convivência que mantemos com a natureza e que implica atitudes, valores, ações. Trata-se de uma opção de vida por uma relação saudável e equilibrada, com o contexto, com os outros, com o ambiente mais próximo, a começar pelo ambiente de trabalho e pelo ambiente doméstico (GADOTTI, 2001, p. 99).

Assim, a EA é uma grande aliada para a construção de valores voltados para a formação do sujeito ecológico. Esse sujeito é definido por Carvalho (2008, p.67) como "[...] um sujeito ideal que sustenta a utopia dos que creem nos valores ecológicos, tendo, por isso, valor fundamental para animar a luta por um projeto de sociedade [...]". Com isso, a partir do momento em que o indivíduo compreende o seu lugar no meio ambiente, pode reivindicar seus direitos, dentre os quais se encontra o direito ao meio ambiente ecologicamente equilibrado, conforme previsto no artigo 225 da Constituição Federal (BRASIL, 1988).

Nas últimas décadas, a EA foi desenvolvida comumente na escola como um tema transversal, cuja abordagem, segundo os Parâmetros Curriculares Nacionais (PCN, 1997), se faz de diferentes formas e de maneira integrativa a partir de projetos que promovam ações socioambientais no ambiente escolar. Na Base Nacional Comum Curricular (BNCC), a EA é abordada como competência geral da educação básica, visão sustentável do ambiente e importância de atitudes que contribuam para a sua melhoria, conforme exposto na competência 10 (BNCC, 2018, p. 10):

Agir pessoal e coletivamente com autonomia, responsabilidade, flexibilidade, resiliência e determinação, tomando decisões com base em princípios éticos, democráticos, inclusivos, sustentáveis e solidários.

É neste contexto que a horta escolar pode servir de ferramenta integradora entre a escola e a comunidade à sua volta, visto que proporciona 
práticas para todos os seus integrantes, colocando os professores e demais profissionais como modelos positivos para os alunos e a comunidade em que estão inseridos (IRALA; FERNANDEZ, 2001).

No entanto, conforme Paulo Freire (FREIRE, 1996, p.52):

Nada, o avanço da ciência e/ou da tecnologia, pode legitimar uma "ordem" desordeira em que só as minorias do poder esbanjam e gozam enquanto às maiorias em dificuldades até para sobreviver se diz que a realidade é assim mesmo, que sua fome é uma fatalidade do fim do século. Não junto a minha voz à dos que, falando em paz, pedem aos oprimidos, aos esfarrapados do mundo, a sua resignação. Minha voz tem outra semântica, tem outra música. Falo da resistência, da indignação, da "justa ira" dos traídos e dos enganados. Do seu direito e do seu dever de rebelar-se contra as transgressões éticas de que são vítimas cada vez mais sofridas.

Com este pressuposto freireano, a EA deve voltar-se para questões sociais como a da Segurança Alimentar, que é importante na vida das pessoas em um país com tamanha desigualdade social como é o Brasil, em que grande parte da população não possui acesso a uma alimentação balanceada que permita uma vida de qualidade e com saúde.

É importante salientar, contudo, que o país conta com a Lei n.11.346 (BRASIL, 2006), que estabelece a Política Nacional de Alimentação e Nutrição (PNAN). Essa mesma lei cria o Sistema Nacional de Segurança Alimentar e Nutricional (Sisan), que define Segurança alimentar como:

A segurança alimentar e nutricional consiste na realização do direito de todos ao acesso regular e permanente a alimentos de qualidade, em quantidade suficiente, sem comprometer 0 acesso a outras necessidades essenciais, tendo como base práticas alimentares promotoras da saúde que respeitem a diversidade cultural e que sejam ambiental, cultural, econômica e socialmente sustentáveis (BRASIL, 2006)

A segurança alimentar e nutricional tem que abranger a promoção não apenas da saúde, visto que deve incluir, além da nutrição alimentar, grupos da população em situação de vulnerabilidade social ou similares. Segundo a essa norma, "[...] um conjunto de políticas públicas, propõe respeitar, proteger, promover e prover os direitos humanos à saúde e à alimentação" (BRASIL, 2013).

As hortas urbanas, sejam elas elaboradas em ambientes de ensino formal ou em espaço não-formal, quando integradas e aliadas à EA, 
contribuem com tal política e exercem um papel na formação do indivíduo. Podem, de fato, desempenhar uma melhoria da alimentação, da segurança alimentar e, consequentemente, na qualidade de vida da comunidade envolvida na ação, inclusive aquela no entorno da horta. As hortas comunitárias estão cada vez mais presentes nos espaços urbanos, sendo por seus habitantes utilizadas e, segundo Farfán et al. (2008, p.24), "os Aspectos tecnológicos, sociais e econômicos da AUP (agricultura urbana e Peri urbana) aliados à agroecologia permitem enquadrar a agricultura urbana agroecológica na definição de tecnologia social, adotado pelo Instituto de Tecnologia Social ITC, Brasil' (2004).

Em Campo Grande, capital de Mato Grosso do Sul, a Agência de Desenvolvimento Agrário e extensão rural - Agraer e a Secretaria do Estado de Meio Ambiente, Desenvolvimento Econômico, Produção e Agricultura Familiar - SEMAGRO, em parceria com a Prefeitura de Campo Grande (Sedesc) e o Governo Federal, desenvolvem um projeto cuja meta é a revitalização e reorganização de 80 hortas urbanas comunitárias já existentes, além da criação de 40 novas hortas em 2019. Para 2020, estava prevista a criação de 80 novas hortas e mais de 10 pontos de comercialização, conforme noticiado na SEMARGO (VENTORIM; SAMARGO, 2019).

Para que as hortas cumpram seu papel educativo e se constituam em ações de Educação Ambiental, é necessário que os projetos de sua elaboração sejam comunitários e desenvolvidos como ferramentas de compreensão sobre os temas específicos ligados à produção dos vegetais, bem como medida de aquisição de habilidades e competências voltadas ao exercício da coletividade, cooperação, entre outras.

Tais características estão relacionadas com o que se deseja numa EA crítica, entendida como portadora da defesa de causas sociais e coletivas, que não ignora o cotidiano, sendo emancipatória e voltada à transformação, ou seja, que englobe as múltiplas esferas da vida social (LOUREIRO, 2012, p. 103).

O interesse pela EA e pelas hortas comunitárias e, sobretudo, o alcance que tem tal proposta na vida das pessoas, motivou a presente pesquisa, cujo objetivo geral é identificar e analisar o panorama de publicações e produções de pesquisa no Brasil que abrangem o papel de hortas em ambientes urbanos no ensino e na promoção da segurança alimentar.

Espera-se que os resultados da investigação contribuam com o desenvolvimento da EA por meio da reflexão sobre os impactos positivos das hortas para a alimentação e, consequentemente, na qualidade de vida das pessoas em seus ambientes. 


\section{Metodologia da Investigação}

A investigação foi realizada por meio de pesquisa bibliográfica/documental, em uma perspectiva quali-quantitativa. Segundo André (2001), tal modalidade possui grande importância no campo da pesquisa, visto que as revisões de pesquisas bibliográficas, além de produzirem dados novos, podem apontar alguma fragilidade metodológica de um campo de pesquisa que, de outra forma, dificilmente seria percebida.

A coleta dos dados foi realizada em sites de produção científica no Brasil (em português ou inglês), num recorte de tempo que compreende o período de 2016 a 2020, entre os meses de setembro de 2016 a novembro de 2020. As plataformas utilizadas foram o Google Scholar (Google Acadêmico) e a SciELO, sendo a coleta de dados realizada por meio dos seguintes descritores:

1- Agricultura Urbana e Educação Ambiental;

2- Horta Escolar e Educação Ambiental;

3- Horta Comunitária e Educação Ambiental;

4- Hortas Urbanas e Educação Ambiental;

5- Qualidade de Vida e Educação Ambiental;

6- Segurança Alimentar e Educação Ambiental.

Com os resultados iniciais alcançados (30 para cada descritor), foi estipulado um máximo de 5 resultados para análise. Para o caso de que se obtivesse o resultado máximo de cada descritor, obter-se-ia 60 resultados para as duas plataformas. Foram utilizados os seguintes critérios de inclusão para a organização e análise: possuir os descritores no título, resumo e/ou palavraschave, bem como artigos que abrangiam educação formal e informal. Os critérios de exclusão, por sua vez, foram: trabalhos voltados exclusivamente para a área de saúde e que não abrangessem a educação. Foram considerados trabalhos publicados em revistas, teses e monografias e artigos.

\section{Resultados e Discussão}

Com a organização dos dados, chegou-se ao resultado de 20 artigos da plataforma Google Acadêmico e 1 artigo da SciELO. Embora o levantamento considerasse trabalhos publicados em revista, teses e monografias e artigos, apenas aqueles em forma de artigo se encaixaram nos critérios de inclusão, sendo tais manuscritos oriundos de revistas, congressos, cadernos, periódicos e anais.

Os descritores 1, 2, 3, 4 e 6 possuíram resultados no Google Acadêmico. O descritor 5, por sua vez, possuiu apenas um trabalho na SciELO, conforme indicado na Figura 1.

revista brasileira educação ambiental 


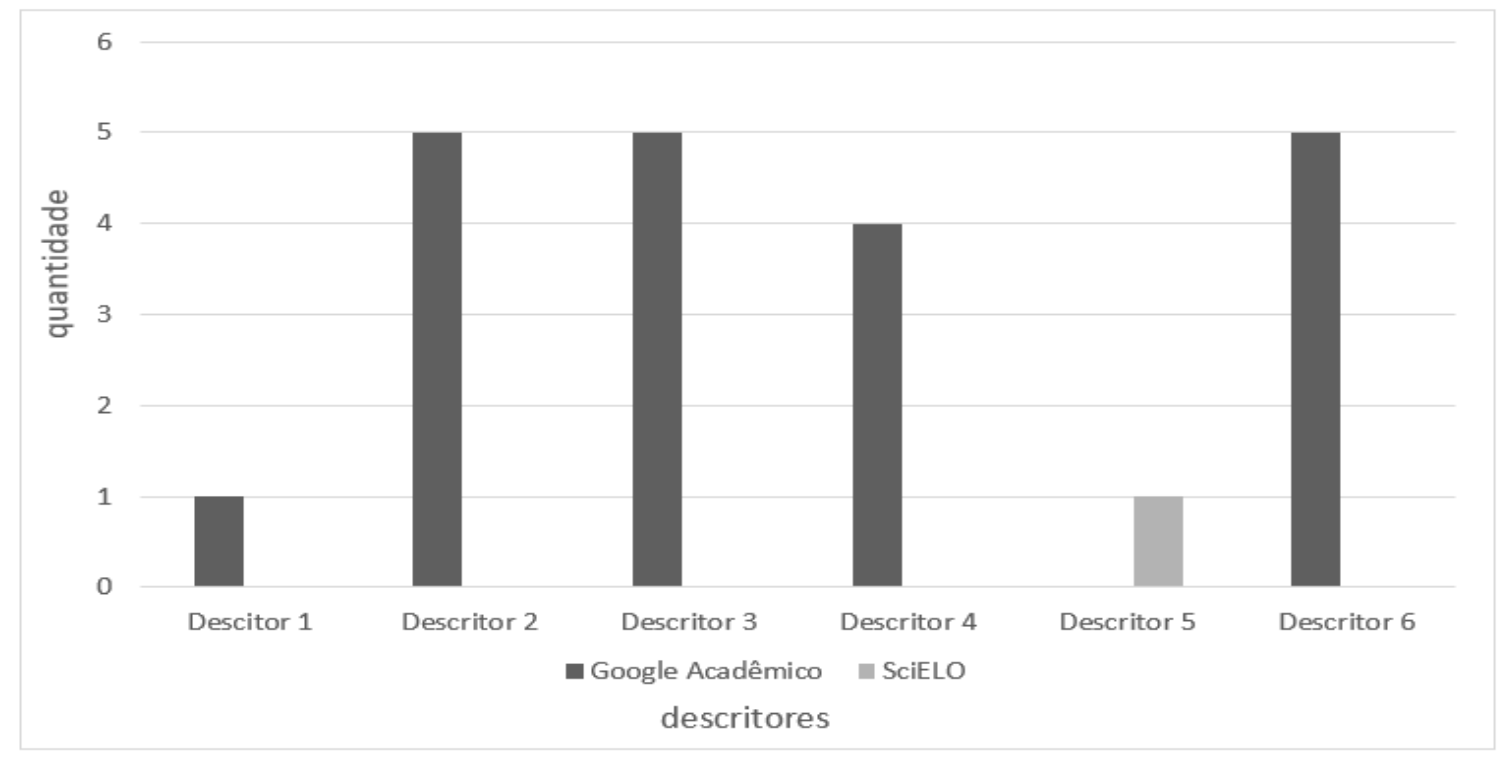

Figura 1: Resultados das quantidades encontrados nas plataformas de pesquisa com os 6 descritores. Fonte: autoral.

Os artigos obtidos estão apresentados em quadros, nos quais se explicita a plataforma proveniente, o título, autores, tipo de publicação, local de publicação, ano de publicação, instituição, região do país e local da horta.

No descritor 1 (Agricultura Urbana e Educação Ambiental), foi obtido apenas um resultado. Quando feita a pesquisa na plataforma SciELO, obtevese um total de zero resultados. No Google Acadêmico, por sua vez, obteve-se aproximadamente 15.300 resultados em 0,09 segundos, dos quais apenas um artigo entrou nos critérios de inclusão, como é possível ver na sua análise (Figura 2).

\begin{tabular}{|lll|}
\hline & \multicolumn{3}{c|}{ Resultado 1 } \\
Plataforma de pesquisa & Google Acadêmico & \\
Título & Agricultura urbana como prática \\
& alternativa para Educação \\
& Ambiental: uma proposta de \\
& sistematização e ações em São \\
& Luís (MA) & \\
Autores & Jairo Fernando Pereira Linhares \\
& Mariano Oscar Aníbal Ibañez \\
& Rojas & \\
Tipo de publicação & Maria Ivanilde de Araujo \\
Local de publicação & Rodrigues & \\
Ano & Artigo & \\
Instituição & Revista brasileira de Educação \\
& Ambiental & \\
Região do pais & 2018 & \\
Local da Horta & Pesquisador Independente, IFMA, \\
\hline
\end{tabular}

Figura 2: Agricultura Urbana e Educação Ambiental (descritor 1). Fonte: autoral.

Revbea, São Paulo, V. 16, № 3: 473-488, 2021. 
Neste caso, o artigo é proveniente da região Nordeste do país, sendo analisado novamente nos descritores 4 e 6 (Hortas Urbanas e Educação Ambiental e Segurança Alimentar e Educação Ambiental, respectivamente).

Os resultados da pesquisa referente ao descritor 2 (Horta Escolar e Educação Ambiental) evidenciaram zero resultados na plataforma SciELO. No Google Acadêmico, por sua vez, obteve-se 12.700 resultados em 0,06 segundos, sendo, ao final, selecionados 5 artigos produzidos nas regiões Centro-Oeste, Norte e Nordeste do país (Figura 3). Pelo fato de o descritor citar horta escolar, todas as hortas referentes aos artigos estavam em ambiente escolar, utilizando a educação formal.

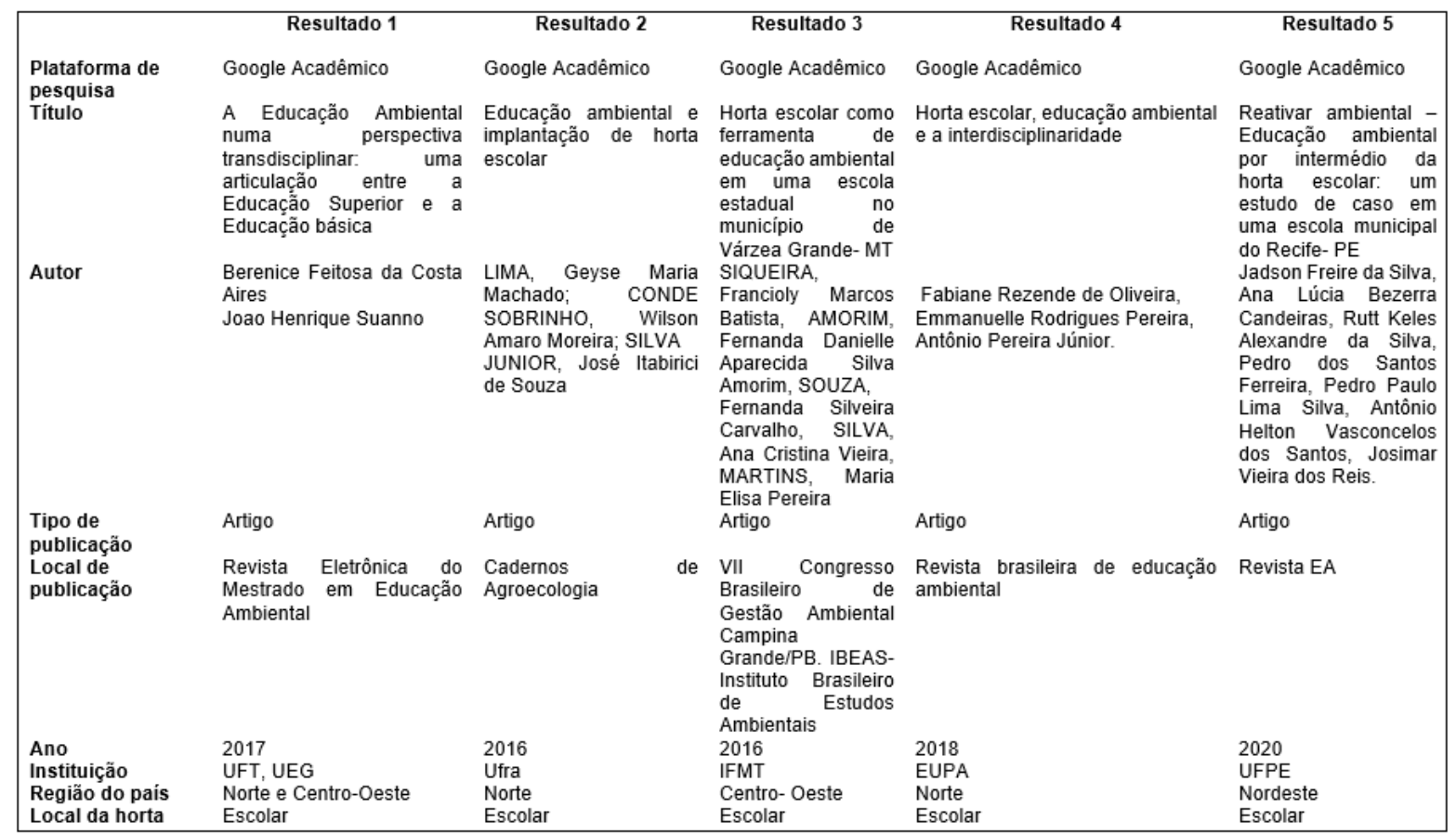

Figura 3: Horta Escolar e Educação Ambiental (descritor 2). Fonte: autoral.

Para o descritor 3 (Horta Comunitária e Educação Ambiental) também foram analisados 5 artigos do Google Acadêmico dentre os aproximadamente 11.200 em 0,08 segundos que foram obtidos. A ausência de resultados para a SciELO persistiu. Neste descritor, os locais em que as hortas estavam não se restringiram a apenas uma categoria, sendo uma em âmbito escolar, duas em universidades e duas em centros urbanos. Em relação às regiões em que a pesquisa foi desenvolvida, obtivemos dados do Sul, Sudeste e Centro-Oeste, não abrangendo, portanto, as regiões Norte e Nordeste como no descritor 2 (Figura 4). 


\begin{tabular}{|c|c|c|c|c|c|}
\hline & Resultado 1 & Resultado 2 & Resultado 3 & Resultado 4 & Resultado 5 \\
\hline $\begin{array}{l}\text { Plataforma de } \\
\text { pesquisa }\end{array}$ & Google acadêmico & Google acadêmico & Google acadêmico & Google acadêmico & Google acadêmico \\
\hline Título & $\begin{array}{lr}\text { A Educação } & \text { Ambiental em } \\
\text { uma } & \text { Comunidade } \\
\text { Reassentada: } & \text { dilemas } \\
\text { socioambientais } & \end{array}$ & $\begin{array}{l}\text { Horta comunitária de } \\
\text { base agroecológica: uma } \\
\text { experiência prática de } \\
\text { educação ambiental, } \\
\text { segurança alimentar e } \\
\text { participaçãa social }\end{array}$ & $\begin{array}{l}\text { Horta comunitária para } \\
\text { promoçãa da educação } \\
\text { ambiental e segurança } \\
\text { alimentar: experiênncias e } \\
\text { perspectivas futuras }\end{array}$ & $\begin{array}{l}\text { Hortas comunitárias } \\
\text { como ferramenta de } \\
\text { sensibilização para } \\
\text { educação ambiental: } \\
\text { estudo de caso em } \\
\text { pequeno município no rio } \\
\text { grande do Sul }\end{array}$ & $\begin{array}{l}\text { Hortas comunitárias: } \\
\text { espaço público que } \\
\text { contribui para } \\
\text { desenvolvimento } \\
\text { sustentável da cidade de } \\
\text { São Paulo, SP }\end{array}$ \\
\hline Autor & $\begin{array}{l}\text { Marilise Oliveira Mesquita, } \\
\text { Tatiana Souza de Camargo, } \\
\text { Themis Kerber Horn, Maria } \\
\text { Luiza Vargas, Elis Mesquita } \\
\text { Horn e Luana Gabriele } \\
\text { Gomes Camelo }\end{array}$ & $\begin{array}{l}\text { Nathan Pereira Dourado } \\
\text { e Naiara Aparecida } \\
\text { Franco }\end{array}$ & $\begin{array}{l}\text { Nathan Pereira Dourado; } \\
\text { Breno Régis Santos; } \\
\text { Naiara Franco Baroni; } \\
\text { Verônica Gronau Luz }\end{array}$ & $\begin{array}{lr}\text { Daniela } & \text { Limberger, } \\
\text { Mateus } & \text { Menezes } \\
\text { Straceione } & \end{array}$ & $\begin{array}{l}\text { Raiza Indyra Rodriges } \\
\text { Rocha, Ana Paula } \\
\text { Branco do Nascimento, } \\
\text { Maria Solange Francos }\end{array}$ \\
\hline Tipo de publicação & Artigo & Artigo em Anais & Artigo & Artigo & Artigo \\
\hline $\begin{array}{l}\text { Local de } \\
\text { publicação }\end{array}$ & Revista da Extensão & $\begin{array}{l}\text { Cadernos } \\
\text { Agroecologia }\end{array}$ & $\begin{array}{l}7^{0} \text { Congresso Brasileiro } \\
\text { de extensão universitária }\end{array}$ & $\begin{array}{l}\text { VIII Congresso Brasileiro } \\
\text { de Gestão Ambiental } \\
\text { Campo Grande/MS }\end{array}$ & $\begin{array}{lr}\text { Periódico } & \text { Técnico e } \\
\text { Científico } & \text { Cidades } \\
\text { Verdes } & \end{array}$ \\
\hline Ano & 2019 & 2017 & 2016 & 2017 & 2019 \\
\hline Instituiç̧ão & UFRGS & UFLA, UNICAMP & UNIFAL, UFGD & UERGS & UNINOVE \\
\hline Região do país & Sul & Sudeste & Sudeste, Centro-Oeste & Sul & Sudeste \\
\hline Local da horta & Escolar & Universidade & Universidade & Centro Urbano & Centro Urbano \\
\hline
\end{tabular}

Figura 4: Resultados do descritor 3- Horta Comunitária e Educação Ambiental.

Fonte: autoral.

A Figura 5 mostra o quadro de análise do descritor 4 (Hortas Urbanas e Educação Ambiental), em que foram obtidos 4 artigos através de pesquisa feita no Google Acadêmico, que apresentou um total de 13.000 resultados em aproximadamente 0,09 segundos. Novamente, a SciELO não apresentou resultado. Neste caso, o artigo resultado da pesquisa do descritor 1 , em que a horta foi desenvolvida numa instituição filantrópica, reaparece. As hortas descritas nos outros três resultados foram desenvolvidas em centros urbanos, o que indica que, nesse descritor, todos os resultados envolvem educação nãoformal. 


\begin{tabular}{|c|c|c|c|c|}
\hline & Resultado 1 & Resultado 2 & Resultado 3 & Resultado 4 \\
\hline Plataforma de pesquisa & Google acadêmico & Google acadêmico & Google acadêmico & Google acadêmico \\
\hline Título & $\begin{array}{l}\text { A utilização de uma horta } \\
\text { orgânica urbana para } \\
\text { promoçãa da educação } \\
\text { ambiental e propagação do } \\
\text { conhecimento agroecológico }\end{array}$ & $\begin{array}{l}\text { Agricultura urbana como } \\
\text { prática alternativa para } \\
\text { educação ambiental: uma } \\
\text { proposta de sistematização e } \\
\text { ações em são luís (MA) }\end{array}$ & $\begin{array}{l}\text { Projeto Hortas Urbanas e } \\
\text { Periurbanas do município de } \\
\text { Tramandaí }\end{array}$ & $\begin{array}{l}\text { Sustentabilidade urbana e } \\
\text { políticas públicas: as } \\
\text { potencialidades das hortas } \\
\text { urbanas em Curitiba e pinhais } \\
\text { (PR) }\end{array}$ \\
\hline Autor & $\begin{array}{l}\text { COSTA, Rafaela; ANJOS, } \\
\text { Mark Pereira; BARBOSA, } \\
\text { Adriana Dalo Rodrigues; } \\
\text { OLIVEIRA, Caio Gabriel } \\
\text { Gomes }\end{array}$ & $\begin{array}{l}\text { Jairo Fernando Pereira } \\
\text { Linhares, Mariano Oscar } \\
\text { Aníbal Ibañez Rojas, Maria } \\
\text { Ivanilde de Araujo Rodrigues }\end{array}$ & $\begin{array}{l}\text { Ricardo De Sampaio Dagnino, } \\
\text { Rejane Margarete Schaefer } \\
\text { Kalsing, Hector Cardoso Do } \\
\text { Amaral, Renan Teixeira Luiz }\end{array}$ & Felipe Comitre \\
\hline Tipo de publicação & Artigo & Artigo & Resumo em anais & Artigo \\
\hline Local de publicação & Cadernos de Agroecologia & $\begin{array}{l}\text { Revista brasileira de } \\
\text { educação ambiental }\end{array}$ & $\begin{array}{l}\text { Anais da Mostra de Ensino, } \\
\text { Extensão e Pesquisa do } \\
\text { Campus Osório-MoExP. }\end{array}$ & $\begin{array}{l}\text { Revista Mundi Sociais e } \\
\text { Humanidades }\end{array}$ \\
\hline Ano & 2018 & 2018 & 2019 & 2019 \\
\hline Instituição & IFSULDEMINAS & $\begin{array}{l}\text { Pesquisador independente, } \\
\text { IFMA. UEMA }\end{array}$ & IFRS & IFPR \\
\hline Região do país & Sudeste & Nordeste & Sul & Sul \\
\hline Local da horta & Centro Urbano & Instituiç̧ão Filantrópica & Centro Urbano & Centro Urbano \\
\hline
\end{tabular}

Figura 5: Hortas Urbanas e Educação Ambiental (descritor 4). Fonte: autoral.

Em relação ao descritor 5 (Qualidade de Vida e Educação Ambiental), na pesquisa no Google Acadêmico foram obtidos aproximadamente 16.000 resultados em 0,10 segundos. Ao analisar os 30 resultados limites, contudo, constatou-se que todos se encaixavam nos critérios de exclusão da pesquisa. Em contrapartida, na plataforma SciELO foram obtidos 18 resultados da pesquisa, dentre os quais, um artigo, que se adequou aos critérios de inclusão (Figura 6).

Compreende-se que o descritor qualidade de vida não abrangeu nenhum tipo de horta, o que evidência, infelizmente, que as hortas não se encontram associadas à qualidade de vida da população. $O$ artigo analisado abrange o ensino, mais especificamente, a Educação Ambiental, o que o fez ser incluído nos resultados do trabalho.

$\mathrm{Na}$ coleta com o descritor 6 (Segurança Alimentar e Educação Ambiental), a plataforma SciELO tornou a obter zero como resultados. No Google Acadêmico foram obtidos aproximadamente 14.900 resultados em 0.07 segundos, dos quais 5 foram analisados (Figura 7), incluindo um que já havia sido incluso nas coletas 1 e 4 . Neste descritor, os locais em que as hortas são desenvolvidas demonstraram ser os mais heterogêneos da pesquisa, sendo instituição filantrópica, abrigo para crianças e adolescentes, centro urbano, universidade e sem horta, apresentando um resultado para cada. Desta forma, tal descritor envolve educação não formal da mesma forma que o descritor 4. 
Resultado 1

$\begin{array}{ll}\text { Plataforma de pesquisa } & \text { SciELO } \\ \text { Título } & \begin{array}{l}\text { Revitalização da Bacia do Ribeirão do } \\ \text { Izidora: educação ambiental como estratégia } \\ \text { Daniela Santos Serpa Siqueira, Daniela de } \\ \text { Almeida Ochoa Cruz, Marcos Vinícius Polignano, } \\ \text { Lenice de Castro Mendes Villela, Vanessa de } \\ \text { Almeida Guerra } \\ \text { Artigo }\end{array} \\ \text { Tipo de publicação } & \text { Saúde Debate } \\ \text { Anocal de publicação } & \text { 2017 } \\ \text { Instituição } & \text { UFMG } \\ \text { Região do pais } & \text { Sudeste } \\ \text { Local da horta } & \text { Sem horta }\end{array}$

Figura 6: Qualidade de Vida e Educação Ambiental (descritor 5). Fonte: autoral.

\begin{tabular}{|c|c|c|c|c|c|}
\hline & Resultado 1 & Resultado 2 & Resultado 3 & Resultado 4 & Resultado 5 \\
\hline Plataforma de pesquisa & Google acadêmico & Google acadêmico & Google acadêmico & Google acadêmico & Google acadêmico \\
\hline Título & $\begin{array}{l}\text { Agricultura urbana como } \\
\text { prática alternativa para } \\
\text { educaçãa ambiental: uma } \\
\text { proposta de } \\
\text { sistematização e ações } \\
\text { em são luís (MA) }\end{array}$ & $\begin{array}{l}\text { Horta agroecológica, } \\
\text { segurança alimentar e } \\
\text { educação ambiental no } \\
\text { lar batista }\end{array}$ & $\begin{array}{l}\text { Horta escolar } \\
\text { agroecológica: } \\
\text { alternativas ao ensino de } \\
\text { Geografia e consciência } \\
\text { ambiental no povoado } \\
\text { Jardim Cordeiro, Delmiro } \\
\text { Gouveia/AL }\end{array}$ & $\begin{array}{l}\text { Preservação do bioma } \\
\text { cerrado e e } \\
\text { aproveitamento } \\
\text { dos frutos nativos na } \\
\text { merenda escolar em } \\
\text { Goiânia no contexto da } \\
\text { educação ambiental }\end{array}$ & $\begin{array}{l}\text { Utilização de hortas } \\
\text { orgânicas como } \\
\text { ferramenta para } \\
\text { Educação Ambiental }\end{array}$ \\
\hline Autor & $\begin{array}{l}\text { Jairo Fernando Pereira } \\
\text { Linhares, Mariano Oscar } \\
\text { Aníbal Ibañez Rojas, } \\
\text { Maria Ivanilde de Araujo } \\
\text { Rodrigues }\end{array}$ & $\begin{array}{l}\text { Marcelo Henrique } \\
\text { Toscano Silva1 } \\
\text { José Pedro Gomes } \\
\text { Galvão, Valéria Sousa } \\
\text { Pereira, Rayele Moraes } \\
\text { Silva, Keile Aparecida } \\
\text { Beraldo }\end{array}$ & $\begin{array}{l}\text { Felipe Santos Silva; } \\
\text { Gabriel da Silva Veras; } \\
\text { Maria de Almeida Soares; } \\
\text { Patrícia Quirino Rocha; } \\
\text { José Rodolfo da Silva } \\
\text { Santos; Ricardo Santos } \\
\text { de Almeida }\end{array}$ & $\begin{array}{l}\text { Harley Anderson de } \\
\text { Souza, Lorena da Cunha } \\
\text { Rodrigues Naves }\end{array}$ & $\begin{array}{lrr}\text { Franciele } & \text { Mara } & \text { Lucca } \\
\text { Zanardo Böhm, Paulo } \\
\text { Alfredo Feitoza Böhm, } \\
\text { Isabelar } & \text { Cristina } \\
\text { Rodrigues, } & \text { Marcelo } \\
\text { Percílio Santana Júnior }\end{array}$ \\
\hline Tipo de publicação & Artigo & Artigo & Artigo & Artigo & Artigo \\
\hline Local de publicação & $\begin{array}{l}\text { Revista brasileira de } \\
\text { educação ambiental }\end{array}$ & $\begin{array}{l}\text { Revista Capim Dourado } \\
\text { Diálogos em Extensão }\end{array}$ & Diversitas Journal & $\begin{array}{l}\text { VII Congresso Brasileiro } \\
\text { de Gestão Ambiental } \\
\text { Campina Grande/PB. } \\
\text { IBEAS-Instituto Brasileiro } \\
\text { de Estudos Ambientais } \\
2016\end{array}$ & $\begin{array}{l}\text { Luminária, União } \\
\text { Vitória }\end{array}$ \\
\hline Instituição & $\begin{array}{l}\text { Pesquisador } \\
\text { independente, IFMA, } \\
\text { UEMA }\end{array}$ & UFT & UFAL, UAB & PUC Goiás, ITS & UEPR \\
\hline Região do país & Nordeste & Norte & Nordeste & Centro- Oeste & Sul \\
\hline Local da horta & Instituição filantrópica & $\begin{array}{l}\text { Abrigo para crianças e } \\
\text { adolescentes }\end{array}$ & Centro Urbano & Sem horta & Universidade \\
\hline
\end{tabular}

Figura 7: Segurança Alimentar e Educação Ambiental (descritor 6). Fonte: autoral. 
Os locais em que as hortas estão inseridas normalmente determinam se a abordagem de educação será formal ou não formal, além de permitirem identificar o possível público das hortas, inclusive aqueles que estão sendo beneficiados com os ensinamentos que the são transmitidos e com a horta propriamente dita.

A Figura 8 evidencia os 19 resultados dos locais das hortas. É importante ressaltar que a diferença entre o número de artigos analisados (21) e o de hortas se dá porque um dos manuscritos analisados aparece três vezes nos resultados. Quanto à abordagem obteve-se que: 6 artigos discorreram acerca de hortas dentro de escolas, 6 em centros urbanos, 3 em universidades, 2 artigos não citam hortas, um em instituição filantrópica e um em abrigo, o que reflete que, por mais que existam hortas em centros urbanos, usando do ensino informal, ainda faltam hortas que visem abastecer locais para os quais, muitas vezes, falta verba pública e privada. Na maior parte das vezes, o agente que propõe as hortas é vinculado a instituições de ensino e orgãos públicos, não sendo organizações privadas tão recorrentes no desenvolvimento de hortas urbanas.

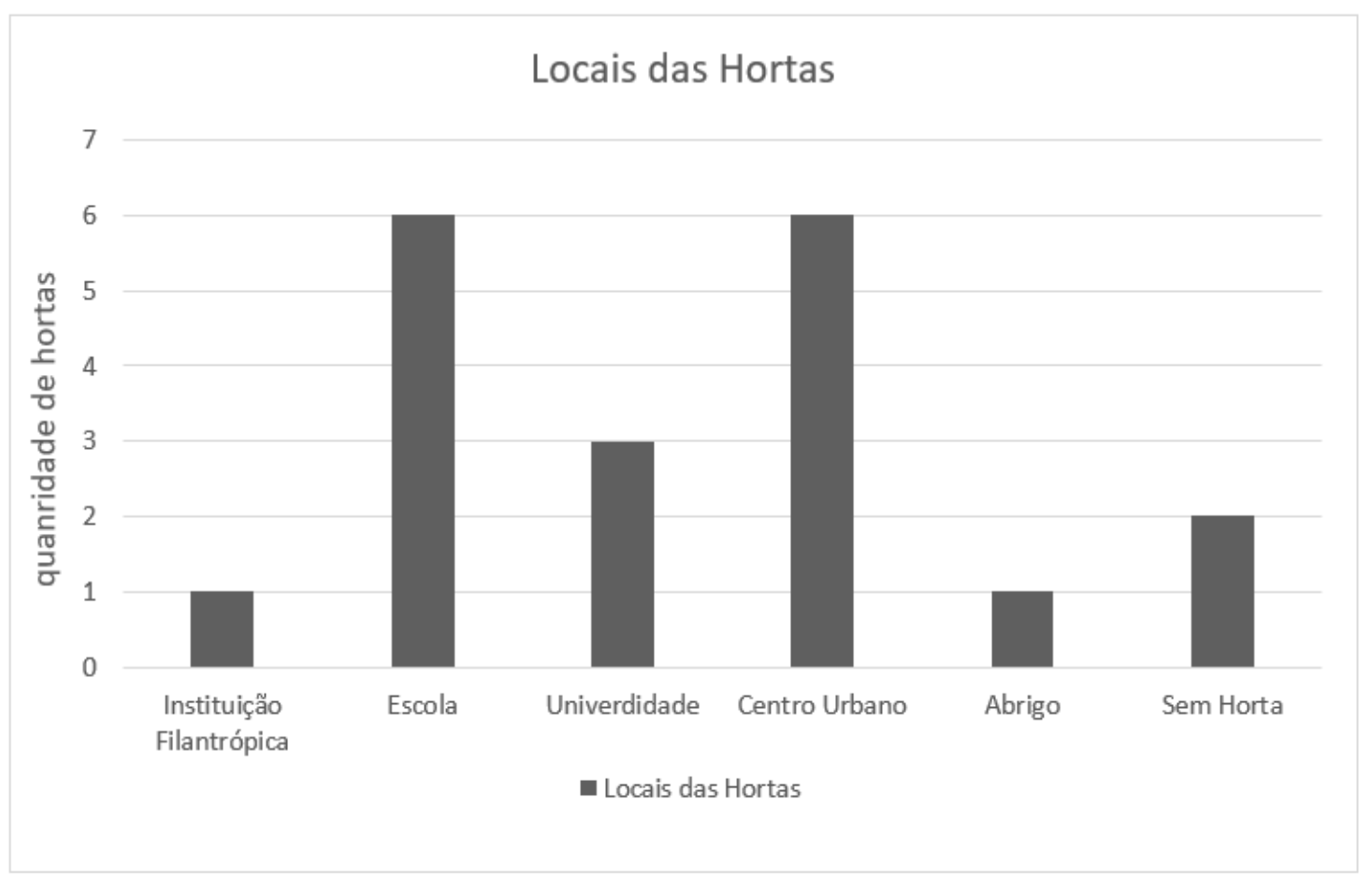

Figura 8: Origem/Locais das Hortas presentes nos artigos analisados. Fonte: autoral.

Os artigos analisados foram produzidos em todas as regiões do país, sendo $21,73 \%$ no Sul, $21,73 \%$, no Sudeste, $21,73 \%$ no Nordeste, $17,39 \%$ no Centro-Oeste e 17,39\% no Norte (Figura 9). 


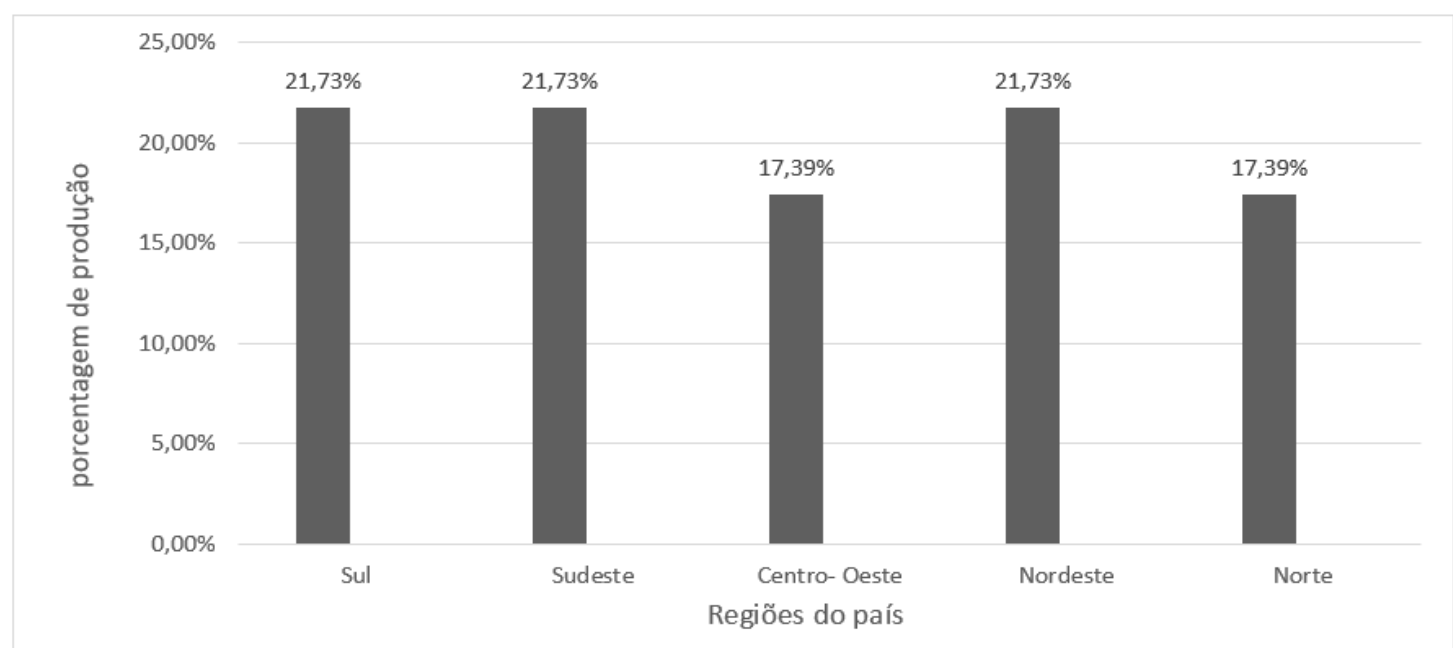

Figura 9: Gráfico mostrando as regiões em que os artigos analisados foram desenvolvidos.

Fonte: autoral.

A maior produção no Sul, Sudeste e Nordeste pode estar relacionada ao fato de que tais regiões apresentam maior PIB (Produto Interno Bruto) em relação às demais, sendo $1.121 .718,3.480 .767$ e 771.663 reais respectivamente, segundo o Instituto Brasileiro de Geografia e Estatística (IBGE, 2017). Com isso, consequentemente, tais regiões podem apresentar produções científicas e ações que implementam hortas mais elevadas, já que a quantidade de recursos disponíveis é maior. Não obstante, as hortas são experiências presentes em todas as regiões do Brasil.

Os artigos analisados trazem hortas em execução ou já finalizadas, encontrando-se os indivíduos engajados nas ações de hortas envolvidos na educação, seja ela formal ou informal. Desta forma, tal educação proporciona um efeito positivo na vida das pessoas pois estas, em conjunto com a prática das hortas, aprendem mais sobre alimentos, cultivo, formas de alimentação e até mesmo meios de geração de renda (DA. Tais conhecimentos podem levar à formação de AUP agroecológicas, que apresentam uma vantagem sobre agricultura familiar rural com menos consumo de combustível e transporte, ausência de mecanismos agrícolas e menor impacto ambiental, resultando num saldo positivo para a sociedade e alimentação (FARFÁN et al., 2008, p.21).

Assim, os resultados apresentaram diversidade de locais em que as hortas estão inseridas, encontrando-se todas envolvidas com processos educativos, sejam eles de educação informal ou formal. $O$ uso da ecopedagogia e da consciência local e planetária (GADOTTI, 2001, p. 125) surgiu em diversos tipos de educação. Além disso, o descritor apresentou influência sobre a quantidade de resultados analisados, já que aqueles que possuíam termos que podiam estar presentes também em temas de saúde apresentaram menor quantidade de resultados relacionados à $E A$, conforme os resultados apresentados para os descritores 5 e 6 , os quais foram os únicos que apresentaram artigos que não mencionavam hortas. 
Ao considerar a quantidade de resultados obtidos em cada pesquisa e os analisados (30 para cada descritor), torna-se evidente a falta de produções científicas sobre o tema, já que em metade dos descritores (1, 4 e 5) não foi obtido a quantidade máxima de resultados estipulada (5 resultados).

A maioria das experiências de hortas é resultante de projetos desenvolvidos pelos autores e/ou analisados por eles, sendo os artigos relatos de tais experiências. Como referência metodológica de investigação, Antônio Carlos Gil aparece como autor mais citado. Outros autores presentes nos textos são os responsáveis pelos subsídios voltados à produção técnica das hortas, sobretudo os que refletem a agroecologia, processos comunitários e projetos urbanos inovadores. Para Dagnino et al. (2019), a "agricultura urbana, além promover a segurança alimentar e nutricional, é também uma forma de promoção da sociodiversidade cultural e de redução das condições de vulnerabilidades de grupos sociais".

A Educação Ambiental presente nas experiências apresentadas nos artigos é referendada por uma variedade de aportes teóricos. Moacir Gadotti é a principal referência nos trabalhos, sendo presente em dois deles. Os artigos também citam propostas de EA como a que discute os Espaços Educadores Sustentáveis. Caso aprofundada, esta proposta poderá se apresentar como uma abordagem teórico-metodológica interessante para se pensar uma horta. Ainda se verificou, em dois trabalhos, a reflexão sobre a interdisciplinaridade e a transdisciplinaridade como fundamentos para compreender o ambiente e as ações nas hortas.

A análise dos resultados sinaliza, contudo, uma lacuna de reflexão epistemológica que possa nortear processos inovadores de ensino e aprendizagem sobre as hortas, tanto nos espaços formais quanto nos espaços não formais. Isto pode ser evidenciado pela falta dos principais autores brasileiros que discutem a epistemologia da EA.

\section{Considerações finais}

A pesquisa revelou que as hortas urbanas, sejam elas ligadas ao ensino formal ou ao não-formal, são experiências presentes em todo o território nacional e exercem um papel importante nos âmbitos ambiental, social e educacional. Contudo, foram observadas poucas publicações e produções científicas no Brasil no período entre 2016 e 2020, o que pode sugerir a necessidade de incentivo às hortas urbanas no intuito de consolidar a Política Nacional de Alimentação e Nutrição (PNAN).

Muitas hortas citadas nos trabalhos foram utilizadas em âmbito escolar, de forma conjunta com ações de Educação Ambiental, de modo a auxiliar no currículo formal e na visão do aluno sobre o meio ambiente. A maior parte das hortas são incorporadas a um conjunto de diversas disciplinas e de atividades escolares, seguindo a premissa de que a EA é um tema transversal de ensino. 
Diversas hortas urbanas também foram desenvolvidas e utilizadas no ensino informal, levando a um enfoque educativo mais voltado à segurança alimentar e em formas de se produzir alimentos, proposta frequentemente ligada à geração de renda para as comunidades do entorno. Grande parte das hortas urbanas são propostas por órgãos públicos, sejam eles de ensino ou não, seguidos por uma menor parcela de instituições privadas.

Conclui-se que a execução de hortas urbanas, aliada a ações de Educação Ambiental, pode exercer um papel fundamental para a comunidade do entorno da horta, facilitando o entendimento dos indivíduos sobre o ambiente que habitam e contribuindo, também, para a valorização de uma alimentação saudável com a inclusão de hortaliças, o que permite que tais indivíduos e seus grupos sociais melhorem a qualidade de vida e tenham uma maior segurança alimentar.

\section{Agradecimentos}

O presente trabalho foi realizado com o apoio da Universidade Federal de Mato Grosso do Sul - UFMS/MEC - Brasil

\section{Referências}

AIRES, B.F.C; SUANNO, J.H. A Educação Ambiental numa perspectiva transdisciplinar: uma articulação entre a Educação Superior e a Educação Básica. Rev. Eletrônica Mestr. Educ. Ambient. Rio Grande, v. 34, n. 2, p. 42-56, maio/ago. 2017.

ANDRÉ, M.E.D.A. Pesquisa em Educação: Buscando Rigor e Qualidade. Cadernos de Pesquisa, São Paulo, v. 113, p. 51-64, 2001.

BÖHM, F.M.L.Z.; BÖHM, P.A.F.; RODRIGUES, I.C.; JÚNIOR, M.P.S. Utilização de hortas orgânicas como ferramenta para Educação Ambiental. Luminária, União da Vitória, v, 19, n. 01, p. 20-26, 2017.

BRASIL. Constituição (1988). Lex: coletânea de legislação, edição federal. São Paulo: Saraiva, 2015.

BRASIL. Ministério da Educação. Base Nacional Comum Curricular. Brasília, 2018.

BRASIL. Lei n. 9795 - 27 de abril de 1999. Dispõe sobre a Educação Ambiental. Política Nacional de Educação Ambiental. Brasília, 1999.

BRASIL. Lei no. 11.346, de 15 de setembro de 2006. Lei de Segurança Alimentar Nutricional, 2006.

BRASIL. Política Nacional de Alimentação e Nutrição - PNAN / Ministério da Saúde. Brasília: Secretaria de Atenção à Saúde. Departamento de Atenção Básica, p.6, 2013.

CARVALHO, I.C.M. Educação Ambiental: a formação do sujeito ecológico. $3^{\text {a }}$ ed. São Paulo: Cortez, 2008. 
COMITRE, F. Sustentabilidade urbana e políticas públicas: as potencialidades das hortas urbanas em Curitiba e Pinhais (PR). Revista Mundi Sociais e Humanidades. Curitiba, PR, v.4, n.01, 42, jan/jul, 2019.

COSTA, R.; ANJOS, M.P.; BARBOSA, A.D.R.; OLIVEIRA, C.G.G. A utilização de uma horta orgânica urbana para promoção da Educação Ambiental e propagação do conhecimento agroecológico. Cadernos de Agroecologia - Anais do VI CLAA, X CBA e V SEMDF - Vol. 13, N 1, Jul. 2018.

DAGNINO, R.S.; KALSING, R.M.S.; AMARAL, H.C.; LUIZ, R.T. Projeto Hortas Urbanas e Periurbanas do município de Tramandaí. Anais da Mostra de Ensino, Extensão e Pesquisa do Campus Osório - MoExP. Disponível em <https://moexp-2021.osorio.ifrs.edu.br/uploads/anai/2019/Anais\%20MoExP\% 202019.1523.pdf>, 2019.

DOURADO, N.P.; FRANCO, N.A. Horta comunitária de base agroecológica: uma experiência prática de Educação Ambiental, segurança alimentar e participação social. Cadernos de Agroecologia - Anais do II SNEA, v. 12, n. 1, Jul. 2017.

DOURADO, N.P.; SANTOS, B.R.; BARONI, N.F.; LUZ, V.G. Horta comunitária para promoção da Educação Ambiental e segurança alimentar: experiências e perspectivas futuras. Anais do $7^{\circ}$ Congresso Brasileiro de Extensão Universitária, 2016.

FARFÁN SJA. 2008. Diagnóstico de hortas comunitárias no dipolo Juazeiro-BA e Petrolina-PE: perfil e demandas de pesquisas. Juazeiro: UNEB. (Dissertação de mestrado).

FREIRE, P. Pedagogia da autonomia: saberes necessários à prática educativa. São Paulo: Paz e Terra, 1996. - (coleção leitura).

GADOTTI, M. Pedagogia da Terra: Ecopedagogia e Educação Sustentável. São Paulo: Peirópolis, 2001.

IBGE. Instituto Brasileiro de Geografia e Estatística. Produto Interno Bruto - PIB. Brasília. 2020. Disponível em: <https://www.ibge.gov.br/explica/pib.php>, Acesso em 9 nov de 2020.

IRALA, C.H.; FERNANDEZ, P.M. Manual para as Escolas: a escola promovendo hábitos alimentares saudáveis, Brasília, p. 1-21, 2001.

LIMA, G.M.M.; CONDE SOBRINHO, W.A.M.; SILVA.JUNIOR, J.I.S. Educação Ambiental e implantação de horta escolar. Cadernos de Agroecologia, v.10, no 3 , 2015.

LIMBERGER, D.; STRACEIONE, M.M. Hortas comunitárias como ferramenta de sensibilização para Educação Ambiental: estudo de caso em pequeno município no rio grande do sul. IBEAS - Instituto Brasileiro de Estudos Ambientais, 2017.

LINHARES, J.F.P.; ROJAS, M.O.A.I.; RODRIGES, M.I.A. Agricultura urbana como prática alternativa para Educação Ambiental: uma proposta de sistematização e ações em São Luís (MA), Revista Brasileira de Educação Ambiental, São Paulo, V. 13, No 1: 10-21, 2018.

LOUREIRO, C.F.B. Para que a Educação Ambiental encontre a educação Introdução. In: LOUREIRO, C.F.B. Trajetória e fundamentos da Educação Ambiental. 4 ed. São Paulo: Cortez, 2012. 
MESQUITA, M.O.; CAMARGO, T.S; HORN, T.K.; VARGAS, M.L.; HORN, E.M.; CAMELO, L.G.G. A Educação Ambiental em uma Comunidade Reassentada: dilemas socioambientais. Revista da extensão, jul 2019/ $\mathrm{n}^{\circ} 18$.

OLIVEIRA, F.R.; PEREIRA, E.R.; JÚNIOR, A,P. Horta escolar, Educação Ambiental e a interdisciplinaridade. Revista Brasileira de Educação Ambiental, São Paulo, v.13, n.2: pp.10-31, 2018.

PCN. Parâmetros Curriculares Nacionais, Meio Ambiente, Saúde. MEC, 1997. Disponível em: <http://portal.mec.gov.br/seb/arquivos/pdf/livro091.pdf>. Acesso em 30 de outubro de 2020.

ROCHA, R.I.R.; NASCIMENTO, A.P.B.; FRANCOS, M.S. Hortas comunitárias: espaço público que contribui para o desenvolvimento sustentável da cidade de São Paulo, SP. Periódico Técnico e Científico Cidades Verdes, ISSN 2317-8604, v.07, n. 16, 2019.

SILVA, M.H.T.; GALVÃO, J.P.G.; PEREIRA, V.S.; SILVA, R.M.; BERALDO, K.A. Horta agroecológica, segurança alimentar e Educação Ambiental no lar batista. Revista Capim Dourado Diálogos em Extensão, v.2, n. 3, 2019.

SILVA, F.S.; VERAS, G.S.; SOARES, M.A.; ROCHA, P.Q.; SANTOS, J.R.S.; ALMEIDA, R.S. Horta escolar agroecológica: alternativas ao ensino de Geografia e consciência ambiental no povoado Jardim Cordeiro, Delmiro Gouveia/AL. Diversitas Journal, v.1, n.3, (set./dez. 2016) pp: 337-346.

SILVA, J.F.; CANDEIAS, A.L.B.; SILVA, R.K.A.; FERREIRA, P.S.; SILVA, P.P.L.; SANTOS, A.H.V.; REIS, J.V. Reativar Ambiental- Educação Ambiental por intermédio da horta escolar: um estudo de caso em uma escola municipal do Recife-PE. Revista EA, 2020.

SIQUEIRA, F.M.B.; AMORIM, F.D.A.S.; SOUZA, F.S.C., SILVA, A.C.V., MARTINS, M.E.P. Horta escolar como ferramenta de Educação Ambiental em uma Escola estadual no município de Várzea Grande - MTIBEAS - Instituto Brasileiro de Estudos Ambientais, 2016.

SIQUEIRA, S.S.S.; CRUZ, D.A.O.; POLIGNANO, M.V.; VILELA, L.C.M.; GUERRAS, V.A. Revitalização da Bacia do Ribeirão do Izidora: Educação Ambiental como estratégia. Saúde Debate, Rio de Janeiro, v. 41, n. Especial, pp. 347-358, jun 2017.

SOUZA, H.A.; NAVES, L.C.R. Preservação do bioma cerrado e o aproveitamento dos frutos nativos na merenda escolar em Goiânia No contexto da Educação Ambiental. Anais do VII Congresso Brasileiro de Gestão Ambiental, Campina Grande/PB - 21 a 24/11/2016.

VENTORIM, K.; SEMARGO, Secretaria de Estado do Meio Ambiente, Desenvolvimento Econômico, Produção e Agricultura Familiar. 2019. Disponível em: <https://www.semagro.ms.gov.br/projeto-de-hortas-urbanas-de-ms-comeca-amudar-cenarios-na-capital/>. Acesso em 30 de nov 2020. 